\title{
We Can Only Do It Together: Addressing Global Sustainability Challenges Through a Collaborative Paradigm
}

\author{
Helen Avery and Birgitta Nordén
}

\section{Introduction}

A consensus is emerging in both scientific circles and international policy discourse that business-as-usual approaches to sustainability have led to a critical state, and that urgent measures are required to reverse these dynamics. At the same time, national and international commitments to address the crisis remain reluctant to reconsider the assumption that growth can continue unchecked (Alexander 2012; Gough 2017; Adloff and Neckel 2019). Indeed, in the Sustainable Development Goals (SDGs), the argument is even made that growth should be encouraged to provide the necessary resources for implementing the goals, and efforts for sustainability in higher education seldom question that paradigm (Ruiz-Mallén and Heras 2020).

In recent decades, we have seen that growth, as such, does not address inequity within or across states, and instead tends to reinforce an extractivist model that concentrates control over resources and key technologies in a small number of hands (Acosta 2013). Technological advances have not offset environmental impacts and emissions continue to rise. Climate change and other environmental impacts continue to disproportionately affect the poorest, destroying the basis of their livelihoods. Both armed conflicts and economic warfare, aimed at control over water, minerals and hydrocarbons, drive internal displacement and forced migration, increasing the number of people worldwide that no state is willing to take responsibility for. It

\footnotetext{
H. Avery ( $\square)$

Centre for Advanced Middle Eastern Studies and Centre for Environmental and Climate Science, Lund University, Lund, Sweden

e-mail: helen.avery@cme.lu.se; helen.avery@1nu.se

Linnaeus University, Växjö, Sweden

B. Nordén

Faculty of Education and Society, Malmö University, Malmö, Sweden

e-mail: birgitta.norden@mau.se
} 
has been constantly repeated, since Rio and before, that the only way to break this vicious cycle is with concerted international action and a paradigm shift (Waddell 2011; Waddock et al. 2015), but we seem no closer to this today than thirty years ago. Economic arguments continue to prevail, and few higher education institutions (HEIs) have chosen to orient their efforts to benefit societies (see Beynaghi et al. 2016).

This study addresses the important issue of how HEIs can achieve sustainability transitions within their own organisations (Miller et al. 2011; Baker-Shelley et al. 2017). Although HEIs contain expertise that is crucial for sustainability, few universities today see sustainability as their main purpose. Each department typically drives its own core mission. As long as the majority of departments and those that are best funded have other main objectives, limited resources will be available for concerted efforts towards sustainability. Indeed, numerous specialisations drive technologies and education that consolidate vested interests and aggravate existing problems, thus contributing to lock-in effects (Payo et al. 2015) and business-as-usual. For HEIs as a whole, this typically creates a conflict between marginalised fields of research or education that see sustainability transitions as their core mission, and all the other sections of the HEI, which strive to maintain the status quo and their current positions within the institutional or disciplinary hierarchies.

Both policy and the literature stress the role of collaboration for sustainability, but relatively little attention has been paid to how we can address the structural drivers in HE that reduce opportunities for collaboration. The present study contributes to this discussion, where we argue that not only competition for funding, but also aspects such as formalised communication or performance assessment have adverse effects. We further argue that ethics and social justice cannot be peripheral considerations. Engagement with actors outside academia has been called for, but often translates into collaboration with large companies rather than citizens. Importantly, most resources in HEIs are still devoted to activities that consolidate societal unsustainability. Rapid changes in higher education are thus urgent and must be coupled with strategies to deal with the disruption that such changes cause, both within academia and in society at large.

What strategies are open to HEIs to create the capacity for real change globally? How can we collectively avoid the points of no-return that our societies appear to be racing towards? Who will be given a say in deciding our future, and which voices are allowed to represent "society"?

HEIs today suffer from much the same paradigm of fragmentation, competition (Shore and Wright 2000; Marginson 2006) and short-sightedness reflected in the formulation of the SDGs, leading to lock-in effects, incrementalism, formalism and the absence of systemic strategic vision. Radical transformation is needed to move beyond the status quo at the speed necessary to address planetary challenges (Vogt and Weber 2020). To achieve this, HEIs need to overcome many obstacles, including funding structures, power imbalances, the disciplinary organisation of knowledge and the absence of future-oriented methodologies. Nevertheless, HEIs still have options available that can open pathways towards a collaborative paradigm (Waddell 2011), 
enabling them to play a positive role in equitable, inclusive and sustainable societal transformation.

\section{The Role of Higher Education in Addressing Global Challenges}

Informed decision-making is an essential component in strategic capacity-building for resilience and sustainable economies, and capacity is needed to generate and provide access to accurate and relevant research. Equally essential is the capacity to creatively use available information; discern causalities, risks and points of leverage; understand complexity and dynamic principles; exercise caution, integrity, benevolence and moral judgement; integrate across disciplines and sectors; take initiative and continuously develop and plan ahead. Foresightful policies will not produce results unless they are combined with the capacity to develop socially and environmentally sustainable technologies, attitudes and organisational forms. New professional competences are needed for the new structures, which means also reforming higher education structures (Avery and Nordén 2017). New practices have to be tried out and refined, resources need to be mobilised, and collaborations and alliances have to be established or consolidated.

These are the classical elements of governance, and by no means new. What is new is the extent to which technology and scientific understanding play a role. Action and access to information is mediated through multiple layers of technology, but also multiple layers of global interaction and institutional configuration. Causes and consequences are no longer transparent, in the sense that they cannot be evaluated based on personal experience alone. Indeed, even collective experience and scientific inquiry only provide partial indications of either causes or consequences, making intelligent and strategic reflection based on dialogue increasingly difficult. Facing such challenges, we need approaches that allow us to make wise decisions (Vogt and Weber 2020) and adequate plans under conditions of great uncertainty, such as working with hypothetical or future scenarios (Schwartz 1991; Gallopín 2002; Goldstein 2009). We are also witnessing the development of other approaches to jointly finding solutions to highly complex problems, for instance in the field of systemic design (Sevaldson 2015).

To function well in times of major changes, the capacity to collaborate and communicate across contexts and collectively envision solutions become central issues. Leadership and initiative, as well as access to resources, are needed to restructure HEIs. But due to the opaqueness of existing knowledge systems (alongside the uncertainties concerning global developments), no single individual, and no single institution, is in a position to take adequate decisions on its own. Open "in-between" spaces are thus singularly important (see Power 1997; Jary 1999; Baker-Shelley et al. 2017; Vogt and Weber 2020), in which joint reflection, dialogue and re-negotiation of roles can take place, independent of particular bias or power relationships. Such in-between 
spaces need to be sufficiently funded, while continuity in interpersonal relationships (Shore and Wright 2000) plays a key role in ensuring effective communication and enabling investment in long-term, deeper reflections.

Crucially, the development of such spaces is obstructed by the paradigm of competition in HEIs (Marginson 2006) that fosters mistrust and a lack of collaboration. Competitive pressures lead to a focus on streamlining and prioritising the here-andnow to generate immediate revenue, rather than investing in the necessary open spaces between institutions, sectors and knowledge fields. An overarching paradigm of collaboration rather than competition is therefore needed to sufficiently prioritise work for the "commons" (Waddell 2011) and the public good.

\section{Blueprint for a New Paradigm in HEIs}

Despite global efforts towards sustainability, the principal drivers of our economies and national policies remain substantially the same. There is, therefore, reason to believe that in the coming years we will see an increase in the adverse effects of business-as-usual, including risks of financial collapse, currency shocks and bankruptcies; the deterioration of working conditions and loss of livelihoods and the incapacity of institutions to provide services or social insurance. We can also expect to see an increase in loss of functionality of automated systems and "hi-tech" as well as an increase in accidents and disasters. Direct climate impacts include the loss of food security and loss of health and adequate living conditions. Among further impacts are increasing inequity, causing extreme stress on family and social support networks, particularly if there is a loss of collective solidarity. Finally, we are already witnessing increasing militarisation, control and surveillance, resulting in a loss of democracy.

In the face of these developments, what kind of knowledge, capacity and competences do we need, and where should HEIs place their priorities?

- To enable action, both trust (Power 1997; Shore and Wright 2000) and hope, as well as the ability to coordinate and mobilise resources, are fundamental conditions (socially, technically and economically in developing new knowledge and capacity).

- For resilience within our institutions and in society (Berkes 2007; Sriskandarajah et al. 2010), we need to develop solidarity, empathy, caring and understanding. Importantly, we must strive to build alliances and teams, prioritise the reduction of risk and vulnerability, and build real capital to maintain margins of action. Essential elements to any strategy are therefore to maintain redundancy and free capacity, rather than to "slim" our organisations. We must plan for multiple scenarios and have the capacity to do so in ways that are in line with facts rather than wishful thinking and rhetoric.

- For agility and creativity, there is an urgent need to develop future-oriented methodologies and stimulate collective action-oriented imagination. Critical 
thinking is key in both teaching and research, which requires us to encourage diversity and complementarity, as well as a sense of initiative and responsibility, rather than conformism and obedience to authority.

- Science has long lived on its reputation for integrity. At a time when science is driven by funding rather than integrity, ethics and trust must again become our top priority if we are not to lose all credibility (Vogt and Weber 2020). New ethical codes of conduct for our professions must be developed to address extreme challenges and new technologies. All activity must be informed by a sense of responsibility, foresight and understanding the consequences of action or inaction while prioritising respect for life, social justice and humanity.

Finally, employees and students at all levels need to develop the capacity to collectively resist inadequate decisions and defend basic conditions for life. We must urgently learn to organise local economies, services and insurance; develop international networks of solidarity and exchange of experience; as well as develop the capacity to invent new technologies and actions needed in regenerative economies.

\section{Knowledge and Policy-Which Knowledge Is Needed in a Time of Systemic Shifts?}

At present, the evaluation of whether a particular policy measure might be suitable for achieving a desired effect tends to be based on evidence with limited relevance for future situations. When we are looking at the most important questions for the survival of our societies, these involve transition and deep-reaching changes in societal and economic structures. It is therefore problematic that a large portion of the evidence on which we base decisions is geared to manage business-as-usual within a given system, rather than considering the issues that arise in transitions between systems.

An important point to remember is that actions that are difficult and costly within one system may be easy and profitable within another, and vice versa. In other words, the relationship between action and impact can change depending on the system. Consequently, any analysis of costs and benefits only applies within the conditions of a particular system. Evidence-based suppositions about the effects of any set of policy measures are also constructed using data from past experiences. The knowledge that we use to drive a certain development is, in other words, valid only within a particular system. This makes it difficult to assess future developments that span across a longer period, particularly if we are interested in transitions across periods with different systemic characteristics, as we are looking at both external and internal uncertainties.

Developing competences, capacity, experience and know-how for any new technology or societal model takes time. By the time resources are mobilised, needs may have already changed and proposed solutions may be outdated. If the required competence and capacity cannot be mobilised sufficiently quickly, countries run the risk of a permanent gap and mismatch between needs and how they are addressed. 
Higher education thus faces a fundamental double constraint: to provide new generations of professionals and researchers with adequate competences and to develop the specific types of scientific knowledge that are needed (see Miller et al. 2011), we must know in advance what these needs will be. At the same time, our forecasting tools cannot provide such answers in an era of rapid and unprecedented change. As in ecosystems, sufficient diversity is therefore essential for HEIs to increase resilience and to create hotbeds in which solutions can reach maturity and be ready for use at the precise moment they are needed.

Such creativity presupposes experimenting at a small scale, and the willingness to accept that the large majority of experiments will not lead to viable solutions. Driving HEIs through "performance" criteria that mainly reward "success" thus blocks one of the most important services HEIs can render. In terms of methodologies, emphasising predictability gears our forecasting tools towards regularity and systemic conditions relevant to the past, rendering them increasingly inadequate to describe a future characterised by systemic instability, variability and conditions that differ from any witnessed before (see Miller et al. 2011; Spangenberg 2019).

\section{Limits to and Risks with the "Technological" Approach}

It has been argued that increasing efficiency, above all through technological means (see, for instance, von Weizsäcker et al. 2014), offers a way out of the situation so that growth can continue through decoupling. While the intelligent use of technology is certainly needed to reduce environmental impacts, over-reliance on technology to solve the major challenges we face today may instead generate new sets of problems that we are not able to solve (see also Adloff and Neckel 2019). Seen globally, improvements through the use of less resource-consuming technologies have been offset by economic growth, demographic growth and the new challenges that appear as various tipping points are reached. Even at the local level, many improvements correspond to outsourcing negative environmental and social impacts to other parts of the planet. Although we may not yet have entirely exhausted all our potentials for growth and expansion, there are limits to indefinite growth (Alexander 2012; Gough 2017; Raworth 2017), and denial amounts to placing the burden of undoing our mistakes on the next generation. Transitions are therefore not simply a matter of developing sustainable alternatives and supporting their implementation, but also involve working proactively with phasing out unsustainable structures and technologies.

All transitions involve deep-reaching rapid change. Although the precise future impacts of different decisions are difficult to assess, certain conclusions can nevertheless be drawn regarding the disruptive effects of change (Miller et al. 2011). One of the fundamental aspects to consider is how to develop the necessary expertise, and how to develop institutions that are capable of continuous development, to respond adequately to the demands that emerge. In times of environmental, technological and societal shifts, much former expertise loses its relevance, and the organisation of 
labour-including the various interrelationships between professions - consequently loses its functionality. Theorists have thus stressed the need for transdisciplinarity (Florin et al. 2015; Mochizuki and Yarime 2015; Vogt and Weber 2020) and epistemological pluralism (Miller et al. 2011) in knowledge construction for the future. Interprofessional collaboration is equally necessary, as well as the capacity to reconfigure organisations and structures. Several approaches additionally suggest more interactive processes, as well as involving concerned populations actively in research (see, for instance, Lynch 2006; Lindhult 2016; Marquard et al. 2016).

\section{Particular Challenges for Universities}

The main challenge that HEIs face today is likely that of funding, regardless of whether they are private- or state-funded. In most contexts, education is oriented towards immediate employability, rather than societal, global or future needs (see Lynch 2006). Similarly, research is dependent on industry funding (Beynaghi et al. 2016) and is largely oriented towards immediate applicability and commercial interests.

The second challenge is the pervasive structure based on competition among students, staff, departments or disciplines, researchers or research environments. Competition systematically prevents available resources from being used effectively and tends to reduce the necessary diversity.

A third major challenge for addressing global challenges is how knowledge is shared and developed. The language of instruction and modes of publication systematically put the Global South at a disadvantage, marginalising Southern perspectives and knowledge production on topics relevant for low-income countries. Hallinger and Chatpinyakoop (2019) have found that in the area of higher education for sustainable development, only a small fraction of publications come from developing countries, and among these, only the larger economies are represented. The issue is aggravated by the fact that scientific methodologies discourage future-oriented explorative approaches and systematically prioritise the aggregation of data rather than contextsensitive descriptions and observations. Not only does this render us collectively blind to emerging trends, but it precludes the development of responses that are relevant and possible to implement in local low-income contexts.

In the short term, HEIs cannot change such underlying structures. But by refusing the competitive paradigm (Chan 2004) and prioritising collaboration-within each HEI as well as with other HEIs nationally and globally-existing resources can be used much more effectively, benefitting from scale, synergies and complementarities. Risks inherent in explorative and innovative research can be shared among partners, while the costs caused by lack of continuity can be reduced, such as those incurred in building and demolishing capacity for disconnected, externally-funded research projects. Importantly, creating a culture of trust and integrity enhances knowledge 
sharing, engagement and teamwork, and enables HEIs to become learning organisations that are open to creativity (Cooke 1987; Pahl-Wostl 2009; Baker-Shelley et al. 2017).

In the current system, funding is earmarked mainly for educational programmes and research projects that do not have sustainability at their core, or which may contribute to global injustice and environmental threats. As academics and academic institutions, we can and should collectively lobby to change such policies. In the meantime, we still have options for action. Existing courses can be restructured to prioritise the ethics and crosscutting competences that are fundamental to sustainability, reading lists and cases can be selected to address actual challenges, and joint courses can be built into programmes to enable collaborative work and transdisciplinary understanding (see the Roskilde model, Andersen and Kjeldsen 2015). Similarly, research projects can be clustered to enable collaboration in directions that are relevant for sustainability transitions, departmental accounting and performance evaluation can be geared to disincentivise competition, while longer-term investments and recruitment can be primarily oriented towards key issues for sustainability.

\section{Why Do We Need Agile Learning Organisations in Higher Education?}

In times of rapid change, institutions alone do not provide a sufficient basis for the trust that enables people to participate in emerging processes, since the stabilising effect of routinised behaviour can interfere with the need to develop new practices (Power 1997; Shore and Wright 2000). Current discussions that phrase these issues in terms of resilience instead stress the significance of a strong social fabric and interpersonal relations (Berkes 2007; Sriskandarajah et al. 2010). Interpersonal relations also play a key role in agility in orienting the development of knowledge and competences in new directions (cf. Miller et al. 2011). This is because knowledge and know-how in contemporary societies have become progressively more "opaque" due to strong specialisation and divisions of labour. Opaqueness includes not only knowledge as a product, but also the instruments, methodologies and structural drivers that underlie knowledge construction. Institutions, therefore, come to mediate relations and communication between professions and between different segments of society. While this regime of work organisation can function as long as changes are slow and incremental, it is subject to collapse if changes accelerate.

In times of rapid and unpredictable change, individuals who can play the role of knowledge brokers and mediate between contexts come to have an increasingly strategic function. Formalised communication becomes increasingly inadequate, since formalised systems are geared to address past conditions rather than current and emerging challenges. At the same time, the need for crosscutting communication increases within, between and beyond HEIs to coordinate new responses to new situations. Brokering carried out by human beings is thus needed across contexts, but 
such brokering presupposes continuity, to enable trust, engagement and quality in communication (Holste and Fields 2010). Equally importantly, trust and continuity in interpersonal relationships are necessary within individual workplaces to deal with change in constructive ways. Strong and continuous interpersonal relationships are required to communicate and renegotiate practices when the initial assumptions underlying formalised steering systems no longer apply. These relationships also make it possible to collaborate effectively and to focus on the tasks at hand.

Inversely, changes that concern roles and performance at the workplace, and possibly also job security, expose employees to considerable stress (Shore and Wright 2000; Miller et al. 2011). Relationships also become "opaque", since the implications of a given action are no longer clear. Responsibilities tend to become confused so that a disproportionate amount of time and attention is needed to find information and to assess developments in the surrounding contexts. With continuous changes and reforms, there is, therefore, a risk that people lose confidence and minimise investment in the future-a process of alienation.

Besides the risk of disengagement, a further serious consequence of continuous change, mobility and weakening of interpersonal relationships is a loss of trust. To compensate, control mechanisms are formalised, but this formalisation tends to lead to rigidity, paralysing constraints and, ultimately, to dysfunctional organisations that block intelligent change (Cooke 1987). In times of structural pressures, when agility, creativity and collaborative intelligence are most needed, a vicious circle of topdown control, formalisation and rigidity can instead occur. The formalised aspects of institutions are frozen solid, while teachers and researchers are treated as dispensable and interchangeable workers on a chain. Higher education fundamentally differs from many other fields of activity to the extent that it is about developing and imparting new knowledge, rather than merely reproducing a pre-defined set of actions according to instructions. Researchers and teachers do their jobs best when they have intrinsic motivation (Marginson 2008) and when their work is in alignment with their values and convictions. Driving academia with principles of Taylorism, top-down steering and external motivation only leads to alienation (Oleksiyenko 2018).

In other words, one of the paradoxes that needs to be addressed in transitions towards sustainability is that to construct relevant decision-making capacity, as well as necessary knowledge and expertise applicable to new situations, existing professional roles and knowledge systems need to be reorganised and re-negotiated, but such changes may also create confusion and anxiety, with risks of top-down steering through formalisation. Thus, although it has been argued that a focus on resilience can delay efforts for mitigation (see Adger 2006; Fiksel 2006; Olsson et al. 2014 for an overview of the debate), maintaining cohesion, autonomy (Vogt and Weber 2020) and continuity are crucial to enable structural changes in HEIs. 


\section{A Role for the SDGs in Higher Education?}

The SDGs are comprehensive, covering most areas of human activity and impacts, and designed for ease of communication across contexts. The SDGs also set concrete targets and provide indicators to measure progress. However, they do not engage in binding commitments for working towards sustainability; rather, they are intended as soft power and as a common vision towards which efforts can be directed. Through mechanisms of monitoring, states worldwide may be incentivised to work more systematically towards the various targets. Within states, the various criteria could be used for evaluations or in decisions on resource allocation. A major merit of the SDGs is the broad emphasis on global equity, but from the perspective of sustainability, the goals do little to reduce the immanent risk of environmental collapse. Additionally, several of the goals are premised on the idea of continued growth (see Ruiz-Mallén and Heras 2020; Vogt and Weber 2020) and the argument that economic growth will liberate the resources needed to realise the SDGs.

Soft power and policy documents at supra-national levels, including the EU, the OECD and UNESCO, have been shown to have a considerable impact on education systems, notably through formalising qualifications that give access to professions in the labour market. It can be expected that although they are not binding, the SDGs will also affect HEIs through the way they are evaluated and possibly through financial incentives. Higher education and research are most directly concerned with SDG 17, which includes knowledge sharing globally (17.6).

Despite the limitations of the SDGs as a basis for supporting transitions towards sustainability and global justice, two of the targets could be used as leverage in higher education. The first is target 4.7 on education for sustainable development. The ethical stance outlined in this target is in line with the values required to build a collaborative paradigm (Waddell 2011) and can, therefore, be used to support transformation in this direction.

The second is target 17.6, on knowledge sharing and access to technology. Unfortunately, in terms of implementation, the indicator for this target is limited to ICTs. Nevertheless, although target 17.6 does not specify that global knowledge sharing should focus on areas that will enable transitions to sustainable societies within planetary boundaries, HEIs can use this target within their respective national evaluation systems to systematically support internationalisation, specifically aiming at global justice and addressing sustainability challenges globally. To make actual contributions, however, internationalisation needs to go beyond its current forms, which are largely geared to serve dominant Northern partners (Chan 2004; Holmarsdottir et al. 2013; Melber 2015). Furthermore, to the extent that mobility is also involved, benefits need to go beyond individual students, staff or research environments, which supposes structures dedicated to spreading knowledge and know-how within the sending and receiving institutions. 


\section{Conclusions}

Regardless of which strategies and pathways are chosen in HEIs, planetary boundaries (Steffen et al. 2015; Raworth 2017) must be respected. The material/ecological limits for sustainable modes of production and consumption are non-negotiable. These limits concern impacts on the planet as a whole, but also the limits of each country and locality. Collapses at any point in our life systems may have irreversible effects and trigger cascades, which means that planetary boundaries need to be considered qualitatively and holistically from their most vulnerable points, rather than only assessed through indicators and geographical or chronological averages. It follows that among the most urgent steps in transforming HEIs is to move away from formalised systems of evaluation, to instead consider capacity, education, collaboration and research based on real impacts on our societies and planetary life systems.

From the arguments outlined in this paper, it would seem that there is a paradox in the need for innovation, mobility and change, on the one hand, and the need for continuity on the other. But if we look closer, we can see that this paradox only exists to the extent that trust, social position, decision-making or innovation are primarily mediated through institutional structures and configurations, and to the extent that communication and reflection are carried by formalised information systems that serve a competitive paradigm. If these various functions are instead carried by humans and mediated through stable teams and interpersonal relationships, collective intelligent action becomes possible.

Despite the urgency of transforming higher education, there is a real danger in reducing academia to serving purely instrumental purposes. Academic freedom with space for critical thinking can prevent blind spots and miscalculations and is essential to preserving democratic values and maintaining credibility in scientific judgement as independent from particular political or commercial interests. Academic freedom is additionally crucial for maintaining foundational and exploratory research, which may provide key insights in the longer term. Diversity of fields of knowledge and academic actors, as well as pluralism in perspectives and methodologies, are vital for the longer-term resilience of our knowledge systems, enabling creativity (Marginson 2008) and preventing group think or perceptual "bubbles". Considering the great uncertainties in how political or environmental issues will unfold in the coming years, critical voices are even more important.

A further key consideration in any strategy to transform HEIs for sustainability, is that although challenge-driven, future-oriented research requires transdisciplinarity (Mochizuki and Yarime 2015), transdisciplinarity in turn depends on functioning and sufficiently stable environments in which disciplinary perspectives can be developed. There is otherwise a risk that research will be reduced to a series of disconnected endeavours locked within specific projects. To create the radical transformation that is needed in the face of global challenges, sufficient attention must be devoted to maintaining diversity, academic freedom, disciplinary expertise and continuity. 
Finally, in any redefinition of priorities and restructuring of HEIs, the most important question is who defines what "sustainability" is, and through which processes new agendas are shaped. All fields and all employees must be involved, and have the time and means to do so-surveys and isolated consultations will not lead to engagement and determination. At the same time, those academics and research environments that are already committed to sustainability and global justice are an invaluable resource and can no longer be marginalised in agenda-setting (Avery and Nordén 2017).

HEIs today are constituted by academics whose disciplinary orientation, expertise and identity have been vested into an unsustainable paradigm. These are the people we have to work with, this is the expertise we have available. Paradoxically, therefore, to be radical, the transformation of HEIs must also be "soft", shaping realistic pathways and incentives for a shift in priorities and space to develop new skills for teachers, administrators and researchers. However, transformation will not be possible as long as sustainability and global justice are seen as add-ons and additional demands on time and resources, on top of a long list of other requirements. The focus must, therefore, lie on dismantling those drivers that otherwise keep sustainability on the margins.

\section{References}

Adger WN (2006) Vulnerability. Glob Environ Change 16(3):268-281

Adloff F, Neckel S (2019) Futures of sustainability as modernization, transformation, and control: a conceptual framework. Sustain Sci 14(4):1015-1025

Alexander S (2012) Planned economic contraction: the emerging case for degrowth. Environ Politics 21(3):349-368

Andersen AS, Kjeldsen TH (2015) Theoretical foundations of PPL at Roskilde university. In: Andersen AS, Heilesen SB (eds) The Roskilde Model: problem-oriented learning and project work. Springer, Cham, pp 3-16

Avery H, Nordén B (2017) Working with the divides: two critical axes in development for transformative professional practices. Int J Sustain High Educ 18(5):666-680

Acosta A (2013) Extractivism and neoextractivism: two sides of the same curse. In: Lang M, Mokrani M (eds) Beyond development: alternative visions from Latin America. Transnational Inst., pp 61-86

Baker-Shelley A, van Zeijl-Rozema A, Martens P (2017) A conceptual synthesis of organisational transformation: how to diagnose, and navigate, pathways for sustainability at universities? J Clean Prod 145:262-276

Berkes F (2007) Understanding uncertainty and reducing vulnerability: lessons from resilience thinking. Nat Hazards 41(2):283-295

Beynaghi A, Trencher G, Moztarzadeh F, Mozafari M, Maknoon R, Leal Filho W (2016) Future sustainability scenarios for universities: moving beyond the United Nations decade of education for sustainable development. J Clean Prod 112(4):3464-3478

Chan W (2004) International cooperation in higher education: theory and practice. J Stud Int Educ $8(1): 32-55$

Cooke RA (1987) The organizational culture inventory. Human Synergistics, Plymouth

Fiksel J (2006) Sustainability and resilience: toward a systems approach. Sustain Sci Prac Policy 2(2):14-21 
Florin P, Guillermin M, Dedeurwaerdere T (2015) A pragmatist approach to transdisciplinarity in sustainability research: from complex systems theory to reflexive science. Futures 65:45-56

Gallopín GC (2002) Planning for resilience: scenarios, surprises, and branch points. In: Gundersen LH, Holling CS (eds) Panarchy. Understanding transformations in human and natural systems. Island Press, Washington, pp 361-392

Goldstein BE (2009) Resilience to surprises through communicative planning. Ecol Soc 14(2):article 33

Gough I (2017) Heat, greed and human need: climate change, capitalism and sustainable wellbeing. Edward Elgar Publishing, Cheltenham and Northampton

Hallinger P, Chatpinyakoop C (2019) A bibliometric review of research on higher education for sustainable development, 1998-2018. Sustainability 11(8):2401

Holmarsdottir HB, Desai Z, Botha LR, Breidlid A, Bastien S, Mukoma W, Nomlomo V (2013) COMPARE forum: the idea of North-South and South-South collaboration. Compare: J Comparative Int Educ 43(2):265-286

Holste JS, Fields D (2010) Trust and tacit knowledge sharing and use. J Knowl Manag 14(1):128-140

Jary D (1999) The implications of the audit society? The case of higher education. In: Dent M, O'Neill M, Bagley C (eds) Professions, new public management and the European welfare state. Staffordshire University Press, Stoke on Trent, pp 29-52

Lindhult E (2016) Co-Production, Action Research and the Movement towards Mode III CoProduction of Knowledge. Paper developed from contribution to Action Research Seminar, Aalborg University. October 7, 2016

Lynch K (2006) Neo-liberalism and marketisation: the implications for higher education. Eur Educ Res J 5(1):1-17

Marginson S (2006) Dynamics of national and global competition in higher education. High Educ 52(1):1-39

Marginson S (2008) Academic creativity under new public management: foundations for an investigation. Educ Theor 58(3):269-287

Marquard M, Sempler M, Mikkelsen H (2016) Transformative learning circles. http://www.cre ativeuniversity.aau.dk/digitalAssets/217/217625_maria-marquard-marianne-sempler-hans-mik kelsen.pdf. Last accessed 11 Mar 2020

Melber H (2015) Knowledge is power and power affects knowledge: challenges for research collaboration in and with Africa. Afr Dev 40(4):21-42

Miller TR, Muñoz-Erickson T, Redman CL (2011) Transforming knowledge for sustainability: towards adaptive academic institutions. Int J Sustain High Educ 12(2):177-192

Mochizuki Y, Yarime M (2015) Education for sustainable development and sustainability science: re-purposing higher education and research. In: Barth M, Michelsen G, Rieckmann M, Thomas I (eds) Routledge handbook of higher education for sustainable development. Routledge, pp 35-48

Oleksiyenko A (2018) Zones of alienation in global higher education: corporate abuse and leadership failures. Tert Educ Manag 24(3):193-205

Olsson P, Galaz V, Boonstra WJ (2014) Sustainability transformations: a resilience perspective. Ecol Soc 19(4):Art. 1

Pahl-Wostl C (2009) A conceptual framework for analysing adaptive capacity and multi-level learning processes in resource governance regimes. Glob Environ Change 19(3):354-365

Payo A, Becker P, Otto A, Vervoort J, Kingsborough A (2015) Experiential lock-in: Characterizing avoidable maladaptation in infrastructure systems. J Infrastruct Syst 22(1):02515001

Power M (1997) The audit society: rituals of verification. Oxford University Press, Oxford

Raworth K (2017) Doughnut economics: seven ways to think like a 21st-century economist. Chelsea Green Publishing

Ruiz-Mallén I, Heras M (2020) What sustainability? Higher education institutions' pathways to reach the Agenda 2030 goals. Sustainability 12(4):1290

Schwartz P (1991) The art of the long view. Doubleday, New York

Sevaldson B (2015) Gigamaps: their role as bridging artefacts and a new Sense Sharing Model. In: Relating systems thinking and design 4. Systemic design research network. Banff, pp 1-11 
Shore S, Wright S (2000) Coercive accountability: the rise of audit culture in higher education. In: Strathern M (ed) Audit cultures: anthropological studies in accountability, ethics and the academy. Routledge, London, pp 57-89

Spangenberg JH (2019) Scenarios and indicators for sustainable development: towards a critical assessment of achievements and challenges. Special Issue. Sustainability $\mathrm{ix}-\mathrm{X}$

Sriskandarajah N, Tidball K, Wals AEJ, Blackmore C, Bawden R (2010) Resilience in learning systems: case studies in university education. Environ Educ Res 16(5-6):559-573

Steffen W, Richardson K, Rockström J, Cornell SE, Fetzer I, Bennett EM, Folke C (2015) Planetary boundaries: guiding human development on a changing planet. Science 347(6223):1259855

Vogt M, Weber C (2020) The role of universities in a sustainable society. Why value-free research is neither possible nor desirable. Sustainability 12(7):2811

von Weizsäcker EU, de Larderel J, Hargroves K, Hudson C, Smith M, Rodrigues M (2014) Decoupling 2: technologies, opportunities and policy options. A Report of the Working Group on Decoupling to the International Resource Panel. UNEP

Waddell S (2011) Global action networks: creating our future together. Palgrave Macmillan

Waddock S, Meszoely GM, Waddell S, Dentoni D (2015) The complexity of wicked problems in large scale change. J Organ Change Manag 28(6):993-1012 